\title{
Oxygen: The Kiss of Life
}

\author{
I am the very air \\ you breathe \\ Your first \\ and last \\ breath
}

\section{—Roger McGough ${ }^{1}$}

Recent guidelines emphasize the importance of an active life for COPD patients, including those with chronic respiratory failure. ${ }^{2}$ Oxygen supplementation increases exercise performances and prevents oxygen desaturation during daily activities in patients with "overt" or "latent" chronic respiratory failure. ${ }^{3}$ This highlights the importance of correctly titrating home oxygen flow for when these patients are at home and/or performing an outdoor activity.

The prescription of long-term oxygen therapy and the titration of the flow rate are based either on resting $\mathrm{P}_{\mathrm{aO}_{2}}$ or exertional desaturation, usually assessed during the 6-min walk test, which does not necessarily mimic real-life situations. ${ }^{4}$ Several conditions may require different oxygen flows, ${ }^{5}$ and some of them are "involuntary" or "mandatory," such as sleeping, defecating, ${ }^{6}$ eating, and digestion, whereas some others are "voluntary," such as walking, gardening, cooking, traveling, sex, and even watching television. If, during these activities, oxygen desaturations are not adequately corrected, they may result in cardiac arrhythmia and eventually transient pulmonary hypertension that may harm the patient's life.

\section{See the Original Study on Page 1901}

\section{and the Case Report on Page 1950}

In this issue of the Journal, Rice et $\mathrm{al}^{7}$ report an elegant randomized trial of a new portable closed-loop oximetrydriven, oxygen-conserving device, the $\mathrm{AccuO}_{2}$, which they compared to standard continuous-flow oxygen and to another oxygen-conserving device (CR-50). They tested the 3 oxygen systems' ability to maintain $\mathrm{S}_{\mathrm{pO}_{2}}$ at $90 \%$, and compared the systems' oxygen consumption/conservation. Their findings confirm data from a randomized controlled trial $^{8}$ of a device that automatically adjusts the oxygen flow based on $\mathrm{S}_{\mathrm{pO}_{2}}$ measurements during a constant-workload test, compared to manual titration by a respiratory therapist.
The merits of the study by Rice et $\mathrm{al}^{7}$ are numerous, including their rigorous methods, the use of 2 controls (ie, continuous flow and CR-50), and the real-life testing with patients, not confined to a laboratory setting, as was the investigation by Cirio and Nava. ${ }^{8}$ By keeping the $\mathrm{S}_{\mathrm{pO}_{2}}$ very constant, at a "desirable" value, the $\mathrm{AccuO}_{2}$ may be useful in patients with preexisting hypercapnia, in whom increasing $\mathrm{P}_{\mathrm{aO}}$ above a certain limit causes deleterious changes to alveolar ventilation and gas exchange, thus worsening acidosis. ${ }^{9}$

The $\mathrm{AccuO}_{2}$ had better oxygen conservation than the CR-50. This is very likely to be associated with a cost saving, which may be considered rather small in absolute terms per patient, but from a larger perspective may result in a quite impressive cost reduction. For example, Rice et al point out that 24 million Americans are affected by COPD, but in other parts of the world the COPD population is much larger: for example, in China it is estimated to be about 110 million.

There are, however, some potential unanswered questions that this investigation ${ }^{7}$ still leaves open. The first is that the patients were using the oxygen devices for 8 hours during the daytime, so their effectiveness in maintaining the target $\mathrm{S}_{\mathrm{pO}_{2}}$ during sleep was not assessed, and in COPD patients' sleep is often associated with more severe hypoxemia and hypercapnia, which in some patients induces substantial cardiovascular effects. ${ }^{10}$

Second, the 3 oxygen-delivery devices were tested on different days, and the patients' activity levels were measured with an actigraph, which calculates the activity levels as counts and therefore does not consider the actual energy expenditure and activity intensity levels, which are the leading causes of hypoxia.

Third, the $\mathrm{AccuO}_{2}$ provides a maximum flow of only $4 \mathrm{~L} / \mathrm{min}$, which is insufficient to guarantee a satisfactory $\mathrm{S}_{\mathrm{pO}_{2}}$ in patients with more severe COPD, especially during exercise.

In keeping with the concept that a sedentary life is not recommended in COPD patients, also in this issue of the Journal, Díaz Lobato and co-workers ${ }^{11}$ present an interesting case report of a patient with overlap syndrome (obesity hypoventilation syndrome plus COPD) who (not on a physician's advice) was simultaneously using night-time noninvasive ventilation (NIV) and supplemental oxygen. The patient also travelled for several days per month. For simplicity he had recently changed from a stationary ox- 
ygen concentrator to a portable pulse-dose concentrator, but he reported that during NIV the "no oxygen delivery" alarm was always on. Díaz Lobato et al tested the patient's combined oxygen and NIV system and found that the concentrator did not detect the patient's inspiratory effort (and therefore did not deliver oxygen) at any of the tested settings. This was probably due to the interference of the inspiratory and expiratory pressures with the concentrator's triggering system.

This case report ${ }^{11}$ is important because it highlights the lack of interaction and exchange between clinicians and manufacturers, which is essential to understand the daily needs of our patients. It is clear to me that the company that developed the portable concentrator was not aware that it might be used during mechanical ventilation, especially in this era where chronic respiratory patients are no longer home-bound. Indeed, the report by Díaz Lobato et $\mathrm{al}^{11}$ focuses our attention on the problem of adding low-flow oxygen during NIV, in ventilators that do not have oxygen blenders. In that setting, supplemental oxygen is often added to the ventilator circuit to maintain an adequate $\mathrm{S}_{\mathrm{pO}_{2}}$, but the $\mathrm{F}_{\mathrm{IO}_{2}}$ is generally unknown, and is influenced by several factors such as the applied pressures, the oxygen flow, and the site where oxygen is added to the circuit. To my knowledge there has been only one study ${ }^{12}$ on this issue, and it found that oxygen should be added close to the exhaust port (ventilator side) of the circuit. If the inspiratory pressure is $>12 \mathrm{~cm} \mathrm{H}_{2} \mathrm{O}$, the oxygen flow should be at least $4 \mathrm{~L} / \mathrm{min}$. The lack of studies on supplemental oxygen during NIV in home ventilators is rather surprising. While most of the ventilator manufacturers have focused their attention on the ventilation algorithms, new ventilation modes, ease of use, and connectivity, they apparently forget to deal with one of the most important issues, which is the best technolog-

The author has disclosed no conflicts of interest.

Correspondence: Stefano Nava MD, Pneumologia e Terapia Intensiva Respiratoria, Policlinico Sant Orsola-Malpighi, via Massarenti no. 9, Bologna 40138 Italy. E-mail: stefano.nava@aosp.bo.it.

DOI: $10.4187 /$ respcare. 01586 ical solution to provide adequate oxygenation to the body tissues. Oxygen is the kiss of life and we badly need to understand how this kiss should be given.

Stefano Nava MD

Pneumologia e Terapia Intensiva Respiratoria Policlinico Sant Orsola-Malpighi Bologna, Italy

\section{REFERENCES}

1. McGough R. Oxygen. In: Collected poems. London: Penguin Books; 2004.

2. Ries AL, Bauldoff GS, Carlin BW, Casaburi R, Emery CF, Mahler DA, et al. Pulmonary rehabilitation. Joint ACCP/AACVPR evidencebased clinical practice guidelines. Chest 2007;13(Suppl 5):4S-42S.

3. Emtner M, Porszasz J, Burns M, Somfay A, Casaburi R. Benefits of supplemental oxygen in exercise training in nonhypoxemic chronic obstructive pulmonary disease patients. Am J Respir Crit Care Med 2003;168(9):1034-1042.

4. Nici L, Donner C, Wouters E, Zuwallack R, Ambrosino N, Bourbeau J, et al. American Thoracic Society/European Respiratory Society statement on pulmonary rehabilitation. Am J Respir Crit Care Med 2006;173(12):1390-1413.

5. Soguel Schenkel N, Muralt BB, Fitting JW. Oxygen saturation during daily activities in chronic obstructive pulmonary disease. Eur Respir J 1996;9(12):2584-2589.

6. Delmastro M, Santoro C, Nava S. Respiratory changes during defecation in patients with chronic respiratory failure. Eur Respir J 2004;23(4):617-619.

7. Rice KL, Schmidt MF, Buan JS, Lebahn F, Schwarzock TK. AccuO oximetry-driven oxygen-conserving device versus fixed-dose oxygen devices in stable COPD patients. Respir Care 2011;56(12):19011905.

8. Cirio S, Nava S. Pilot study of a new device to titrate oxygen flow in hypoxic patients on long-term oxygen therapy. Respir Care 2011; 56(4):429-434.

9. Plant PK, Owen JL, Elliot MW. One year period prevalence study of respiratory acidosis in acute exacerbation of COPD: implications for the provision of non-invasive ventilation and oxygen administration. Thorax 2000;55(7):550-554.

10. Flick MR, Block AJ. Nocturnal vs diurnal cardiac arrhythmias in patients with chronic obstructive pulmonary disease. Chest 1979; 75(5):8-11.

11. Díaz Lobato S, Pérez Rodríguez E, Mayoralas Alises S, Portable pulse-dose oxygen concentrators should not be used with noninvasive ventilation. Respir Care 2011;56(12):1950-1952.

12. Thys F, Liistro G, Dozin O, Marion E, Rodenstein DO. Determinants of $\mathrm{F}_{\mathrm{IO}_{2}}$ with oxygen supplementation during noninvasive two-level positive pressure ventilation. Eur Respir J 2002;19(4):653-657. 